\title{
Antioxidant Activity of Biphenolic Compounds Anchored on Mesoporous Alumina ${ }^{+}$
}

\author{
Vanina A. Guntero ${ }^{1,2}$, Cristián A. Ferretti 1,*, Carla Ormachea ${ }^{1}$, Pedro M. E. Mancini ${ }^{1}$ \\ and María N. Kneeteman ${ }^{1}$ \\ 1 IQAL (UNL-CONICET), Laboratorio Fester-QUÍMICA ORGANICA (FIQ), \\ Universidad Nacional del Litoral, S3000 Santa Fe, Argentina; vguntero@sanfrancisco.utn.edu.ar (V.A.G.); \\ carlaormachea@gmail.com (C.O.); pmemancini@gmail.com (P.M.E.M.); \\ mkneeteman@fiq.unl.edu.ar (M.N.K.) \\ 2 Grupo Productos Naturales, Universidad Tecnológica Nacional (UTN) - Facultad Regional San Francisco, \\ 2400 San Francisco, Argentina \\ * Correspondence: cferretti@fiq.unl.edu.ar; Tel.: +54-342-457-1164 \\ + Presented at the 23rd International Electronic Conference on Synthetic Organic Chemistry, \\ 15 November-15 December 2019; Available online: https://ecsoc-23.sciforum.net/.
}

Published: 14 November 2019

\begin{abstract}
Phenolic antioxidants are used in the industry to delay the oxidation of fats, with the most used being butyl hydroxy anisole (BHA) and butyl hydroxy toluene (BHT). However, the consumer concern regarding their safety has motived the study of natural alternatives. In this sense, the aim of this work was to evaluate the behavior of 3,3'-dimethoxy-5,5'-di-2-propenyl-1,1'-biphenyl-2,2'-diol and 6,6'-dihidroxi-5,5'-dimethoxy-(1,1'-biphenyl)-3,3'-dicarbaldehyde free and supported on mesoporous alumina. Biphenolic compounds were synthetized by radical coupling and then anchored on alumina by microwave assisted process. The antioxidant activity of these compounds was investigated by phosphomolybdenum method. The results showed that biphenolic compounds anchored on mesoporous alumina have a marked antioxidant activity, better than free antioxidants. Biphenolic compounds supported on alumina display antioxidant properties allowing a new opportunity for the developing in food and cosmetics packaging.
\end{abstract}

Keywords: antioxidant activity; phosphomolybdenum method; biphenolic compounds

\section{Introduction}

Additives are substances which are added on foods with a technological objective or to provide a functional property. In this sense, antioxidants are added to foods to minimize rancidity, retard the formation of toxic oxidation products, maintain nutritional quality, and increase shelf life [1].

It is known that methoxyphenols are antioxidant. They owe their activity to the ability to trap the chain-carrying peroxy radicals (ROO) by donation of the phenolic hydrogen atom reaction (Equations (1)), which is a very much faster reaction than the attack of the peroxy radicals on the organic substrate (RH) [2].

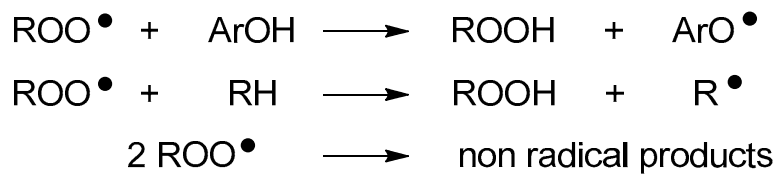

Phenolic compounds could react with free radicals such as $\mathrm{ROO}, \mathrm{RO}, \mathrm{OH}$ and $\mathrm{O}_{2}{ }^{-}$much faster than the phospholipid that is always present at much higher quantities in living cells than the antioxidant [2]. Nowadays the industry uses synthetic antioxidants. However, natural products are increasingly in demand for consumers. In this sense, the aim of this work was to evaluate the behavior 
of two biphenyl compounds, 3,3'-dimethoxy-5,5'-di-2-propenyl-1,1'-biphenyl-2,2'-diol (BiEG) and 6,6'-dihidroxi-5,5'-dimethoxy-(1,1'-biphenyl)-3,3'-dicarbaldehyde (BiVA) free and supported on mesoporous alumina (MA).

Mesoporous alumina was chosen because it has suitable structure, large specific surface area and high pore volume, enabling high loading of active species [3]. Its stability leads to better dispersion, biocompatibility, and subsequent functionalization [4].

\section{Materials and Methods}

\subsection{Synthesis of Biphenolic Compounds}

The synthesis of biphenolic compounds was realized by radical coupling following $[5,6]$. Mesoporous alumina was synthesized in accordance with the published procedure [7] using Pluronic P123 as template. In a typical experiment, the triblock copolymer Pluronic P123 (3 g) and aluminum trichloride $(0.4 \mathrm{~g})$ were dissolved in $60 \mathrm{~mL}$ of ethanol under stirring at $40{ }^{\circ} \mathrm{C}$. Then, aluminum isopropoxide $(6 \mathrm{~g})$ was added to the solution. The solution was maintained at $40{ }^{\circ} \mathrm{C}$ for $2 \mathrm{~h}$, and the surfactant was removed by calcination, which was carried out by increasing the temperature to $400{ }^{\circ} \mathrm{C}$ for $4 \mathrm{~h}$. The supporting of phenolic compounds on mesoporous alumina were performed by a microwave assisted oven procedure [8].

\subsection{Characterization of Biphenolic Compounds}

Biphenolic compounds (BiEG and BiVA) were checked by melting points and spectroscopic studies (IR, 1H-NMR, 13C-NMR). The equipment used to determinate FTIR was a Shimadzu FTIR Prestige-21 spectrophotometer, and magnetic resonance nuclear tests were made on a Bruker DPX-300 (300 MHz) spectrometer.

\subsection{Determination of Antioxidant Activity}

The assay was carried out by phosphomolybdenum method which is based on the reduction of $\mathrm{Mo}(\mathrm{VI})$ to $\mathrm{Mo}(\mathrm{V})$ by the sample and the formation of a green complex. Decrease of absorbance is directly proportional of antioxidant activity of sample [9]. Briefly, the method consisted of preparing solutions of biphenolic compounds in ethanol. Then $1 \mathrm{~mL}$ of sample solution was mixed with $9 \mathrm{~mL}$ of reactive solution and incubate at $95^{\circ} \mathrm{C}$ for $120 \mathrm{~min}$. The absorbance was measure at $695 \mathrm{~nm}$ against a blank on a Perkin Elmer Lambda 20 spectrophotometer. Results obtained were compared with butyl hydroxy toluene (BHT). Antioxidant activity was expressed as inhibition (I) calculated by the equation where As is initial absorbance, As120 is the absorbance of the sample at $120 \mathrm{~min}$, Ac is initial absorbance of control, and Ac120 is the absorbance of control at $120 \mathrm{~min}$ (Equation (2)).

$$
I(\%)=\frac{1-\left(A_{S}-A_{S 120}\right)}{\left(A_{c}-A_{c 120}\right)}
$$

\subsection{Characterization of Materials}

Materials free and with biphenolic compounds anchored were characterized by nitrogen adsorption/desorption isotherms. The measurements were performed with a NOVA-1000 Quantachrome at liquid nitrogen temperature $(77 \mathrm{~K})$. The specific surface areas of the samples were calculated using the Brunauer-Emmett-Teller (BET) method in the relative pressure range of 0.05-0.35. The pore size distribution (PSD) curves were derived from the adsorption branches of the isotherms using the Barrett-Joyner-Halenda $(\mathrm{BJH})$ method. The pore volumes were obtained from the adsorption branches of the isotherms at a partial pressure of 0.99 . Small angle X-ray scattering patterns (SAXS) were realized with a XEUSS 1.0, with Cu K radiation of wavelength $1.54178 \AA$.

\section{Results and Discussion}

Results obtained by FTIR, melting points and NMR confirmed the structures and purity of the compounds. 
$\mathrm{N}_{2}$ adsorption/desorption isotherms of materials are shown in Table 1. BiVA and BiEG anchored on mesoporous alumina caused a reduction on BET surface, pore volume and average pore diameter, which is attributed to the biphenolic compounds found inside the pores of the alumina, reducing the adsorption of nitrogen and consequently the textural parameters of alumina free.

Table 1. Textural parameters of materials.

\begin{tabular}{cccc}
\hline Sample & Specific Surface Area $\left(\mathbf{m}^{2} / \mathbf{g}\right)$ & Pore Volume $\left(\mathbf{c m}^{3} / \mathbf{g}\right)$ & Average Pore Diameter $(\AA)$ \\
\hline MA & 266 & 0.90 & 136 \\
BiVA-MA & 180 & 0.10 & 22 \\
BiEG-MA & 157 & 0.54 & 158 \\
\hline
\end{tabular}

The small angle patterns indicate the presence of a wormlike channel type [7]. For the sample with BiEG and BiVA, the presence of these compounds on MA rises to a decrease in the diffracted intensity (Figure 1).

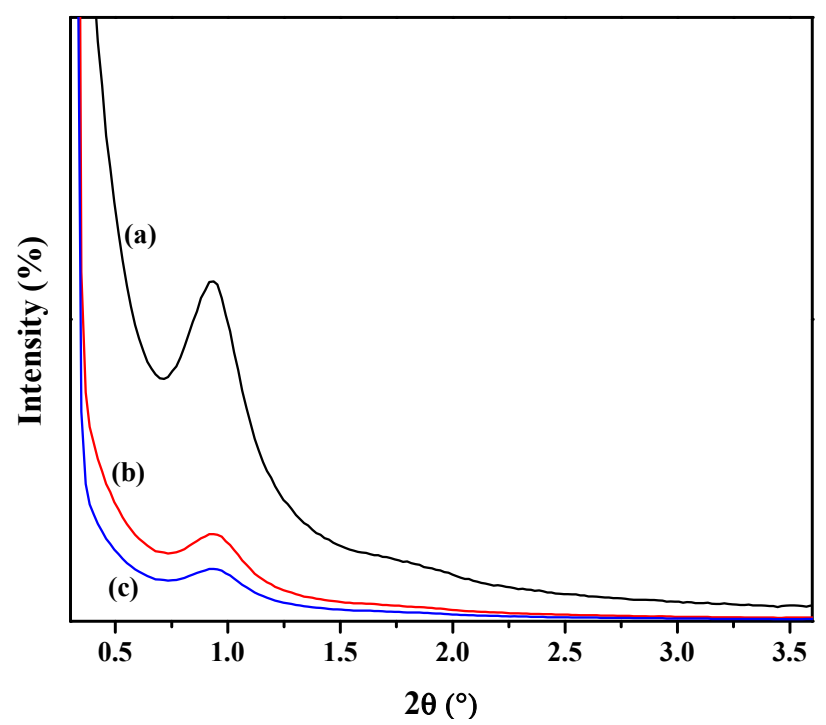

Figure 1. Small angle X-ray scattering patterns of (a) MA, (b) BiVA-MA, (c) BiEG-MA.

To evaluate the antioxidant activity of synthetized materials the phosphomolybdenum method was used. The Mesoporous alumina (MA) did not show antioxidant activity. BiVA and BiEG presented antioxidant properties. Biphenolic compounds anchored on mesoporous alumina presented higher antioxidant activity than those free compounds (Figure 2). 


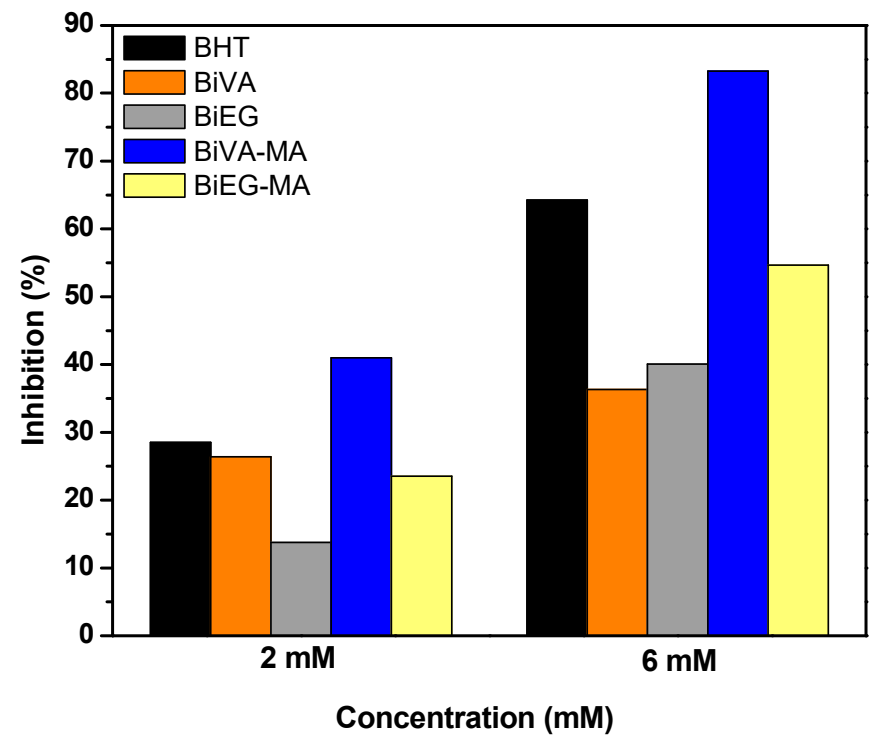

Figure 2. Antioxidant activity of biphenolic compounds free and anchored on mesoporous alumina.

\section{Conclusions}

In summary, biphenolic compounds were synthesized and then anchored on mesoporous alumina through a microwave assisted process. The physicochemical characterization of these materials confirmed the successful anchoring of the compounds into the mesoporous alumina. These systems show higher antioxidant properties when they are anchored on mesoporous alumina, allowing a new opportunity for the developing in food and cosmetics packaging.

Acknowledgments: Authors thank the Agencia Nacional de Promoción Científica y Tecnológica (ANCyT) of Argentina (grant PICT 2014 No. 1587), Universidad Nacional del Litoral (UNL), Santa Fe, Argentina (grant CAI+D 2017), and Universidad Tecnológica Nacional (UTN), San Francisco, Argentina (grant PID 2018 UTN No. 5489) for financial support of this work.

Conflicts of Interest: The authors declare no conflict of interest.

\section{References}

1. Fukumoto, L.R.; Mazza, G. Assessing antioxidant and prooxidant activities of phenolic compounds. J. Agric. Food Chem. 2000, 48, 3597-3604.

2. Fujisawa, S.; Atsumi, T.; Kadoma, Y. Antioxidant and prooxidant action of eugenol-related compounds and their cytotoxicity. Toxicology 2002, 177, 39-54.

3. Zhang, K.; Li, C.; Yu, J.; Gao, S.; Xu, G. Synthesis of texture-excellent mesoporous alumina using PEG1000 as structure-directing agent. Chin. J. Chem. Eng. 2016, 25, 137-141.

4. Tao, Z. Mesoporous silica-based nanodevices for biological applications. RSC Adv. 2014, 4, 18961-18980.

5. A. Farias Dias, "An Improved High Yield Synthesis Of Dehydrodieugenol. Phytochem. Lett. 1988, 27, 3008-3009.

6. Costero, A.M.; Gil, S.; Parra, M.; Mancini, P.M.E.; Kneeteman, M.N.; Quindt, M.I. 5, 5 0-Bis-vanillin derivatives as discriminating sensors for trivalent cations. Tetrahedron Lett. 2015, 56, 3988-3991.

7. Cai, W.; Yu, J.; Anand, C.; Vinu, A.; Jaroniec, M. Facile Synthesis of Ordered Mesoporous Alumina and Alumina-Supported Metal Oxides with Tailored Adsorption and Framework Properties. Chem. Mater. 2011, 23, 1147-1157. 
8. Guntero, V.A.; Ferretti, C.A.; Mancini, P.M.E.; Kneeteman, M.N. Encapsulation Of Compounds Biphenyls Into Sba-15: Synthesis of Composites for Application. Glob. J. Eng. Sci. Res. 2016, 5, 32-37.

9. Alam, N.M.; Bristi, N.J.; Rafiquzzama, M. Review on in vivo and in vitro methods evaluation of antioxidant activity. Saudi Pharm. J. 2013, 21, 143-152.

(C) 2020 by the authors. Licensee MDPI, Basel, Switzerland. This article is an open access article distributed under the terms and conditions of the Creative Commons Attribution (CC BY) license (http://creativecommons.org/licenses/by/4.0/). 